\title{
An Investigation of Saudi EFL University Students' Attitudes towards the Use of Google Translate
}

\author{
Eid Alhaisoni \\ Department of English, College of Arts, University of Ha'il, Saudi Arabia \\ E-mail: Eid.alhaisoni@gmail.com \\ Maha Alhaysony \\ Department of English, College of Arts, University of Ha'il, Saudi Arabia \\ E-mail: m.alhaysony@gmail.com
}

Received: January 20, 2017 Accepted: February 5, 2017 Published: February 7, 2017

doi:10.5296/ijele.v5i1.10696 URL: http://dx.doi.org/10.5296/ijele.v5i1.10696

\begin{abstract}
It is argued that the popularity of Google Translate is increasing and users are implementing this giant search engine for different purposes. Hence, this paper reports the results of a study on attitudes toward the use of Google Translate (GT). The participants were 92 Saudi EFL university English major students. A questionnaire was used as an instrument in this study. The results revealed that almost all of the subjects reported using GT. Vocabulary, writing and reading were the three most frequent purposes for which they use GT, whereas translation was the least frequently used. The results also showed that GT is frequently used to get the meaning of unknown words, writing assignments and reading an English textbook. The findings of the study have implications for students, instructors and researchers.
\end{abstract}

Keyword: Google Translate, Translation Machines, online resources for translators 


\section{Introduction}

In the past, language learners used a dictionary to get meanings of unknown words in the target language. Consulting traditional dictionaries is time-consuming, and L2 learners might face difficulty interpreting the meaning. In today's world of ubiquitous Wi-Fi connections, laptops, tablets and smartphones, foreign language instructors and students have at their fingertips a broad collection of free online resources for translators (FORTs), including powerful machine translation (MT) websites and apps. These online resources have made life easier than before.

Machine translation (MT) as an automated activity is the process by which computer software is used to translate a text from one natural language to another (Hutchin, 1995). Today millions of words are being translated into different languages by people using computers every day, and this number is anticipated to increase exponentially in the near future (Kumar, 2012).

Nowadays, various online (MT) resources available for L2 learners such as Translator Online, Foreign Word, Web Trance, Prompt and Google Translate (GT) (Hampshire \& Salvia, 2010). GT is one of the most common online resources for translation. It is a free multilingual machine translation service developed by Google to translate text, speech, images, sites or real-time video from one language into another. GT is a corpus-based and founded based statistical retrieval of text receiving the language data from huge web data (Kirchhoff, Turner, Axelrod \& Saavedra, 2011). GT is efficient and compatible with PC systems and smart phone systems (i.e., Android and IOS), and these features have made it very popular among users. The progress of GT is visible, and it translates over 100 languages. Hence, studies are needed to explore users' attitudes towards GT accuracy, shortcomings and usefulness. Correspondingly, some researchers have performed survey studies on MT systems (Costa-Juss`a et al., 2012; Fiederer \& O’Brien, 2009; Niño, 2009; Stymne et al., 2011; Wu et al., 2012; Zhao et al., 2013). Few researchers have carried out survey studies on GT (Jolley \& Maimone, 2015; Korošec, 2012). Given the importance of communication and translation, not only do the students of translation make frequent use of MT services, particularly GT, but also learners from various disciplines and fields of study consult GT for translating texts from English into their first language and vice versa. Although it has shortcomings in translating different text types (Jolley \& Maimone, 2015), GT serves 200,000,000 users daily (Wikipedia.org).

In a nutshell, as a result of the analysis and review of studies on MT systems and GT, it was found that most of the studies have examined and evaluated GT through experimental design (Ganjalikhani, 2014; Karnal \& Pereira, 2015; Hampshire \& Salvia, 2010); however, very few studies have focused on student perceptions of GT through a survey (Jolley \& Maimone, 2015; Korošec, 2012). Since GT is widely and increasingly used by students, there is little knowledge about their perceptions and attitudes towards GT accuracy, shortcomings and usefulness (Jolley \& Maimone, 2015). Hence, a survey involving EFL students is required to investigate their views, attitudes and perceptions of GT performance. More specifically, such a study on EFL students in a Saudi context is absent; therefore, studies are needed to fill the 
gap. Hence, this study aims to investigate Saudi EFL university English major students' attitudes toward the use of GT.

\section{Literature Review}

In this section, we will shed light on some studies that have investigated GT in the EFL/ESL context and in the Arab context as well.

Niño (2009) surveyed 16 post-secondary Spanish students who had completed a ten-week course that involved the post-editing of MT output. These students were asked a handful of questions about MT, including whether they planned to use it in the future, if they believed it to be a useful language learning tool, and whether they thought MT post-editing had improved their Spanish in general and their L2 writing in particular. A group of 30 FL 'tutors' also responded to questions about their awareness and personal use of MT and the degree to which they had integrated it into their teaching. Ninety-three per cent of the students reported using FORTs for post-editing, and 69\% said they planned to use FOMT in the future. While $70 \%$ of tutors reported using MT as a 'learning/teaching tool', only $23 \%$ had used it in their lessons (p. 250). Niño concluded, 'Overall, the use of MT and free online MT in FL learning was perceived as an innovative and positive learning experience both by language tutors and language learners $(2009$, p. 253). She also noted an emphasis on the instructional value of introducing advanced FL students to MT in ways that encourage them to understand 'the deficiencies of free online MT output' and raise their 'awareness as to the complexity of translation and language learning' (Niño, 2009, p. 253). She also emphasised the instructional value of introducing advanced FL students to MT in ways that encourage them to understand 'the deficiencies of free online MT output' and raise their 'awareness as to the complexity of translation and language learning' (Niño, 2009, p. 253).

Savoy and Dolamic (2010) examined the effectiveness of GT service in performing a search inquiry using the mean reciprocal rank (MRR) approach. The study reported that the application of the GT tool to automatically translate English topics into French can obtain a retrieval effectiveness of $88 \%$ compared to a monolingual search. In a quality assessment study, Hampshire and Salvia (2010) evaluated the quality of free online machine translators (FOMTs) including GT. First they developed a ranking system and then ranked ten free online machine translators. They found that GT was the most common and popular MT system among users.

Xu and Wang (2011) set out to explore the 'attitudes and knowledge' of Chinese students in a translation training programme about a variety of online translation resources, including online corpora, search engines and professional-grade CAT suites (p. 63). Their survey of 100 students included questions about preferred translation techniques, awareness of different CAT tools, output quality (accuracy and reliability), convenience and frequency of use, and the importance of integrating such tools into translator training curricula. The study revealed two key findings: 'that translation students rely more on electronic resources than non-electronic ones ... and that the underlying reason is convenience, not accuracy' (Xu \& 
Wang, 2011, p. 79). Although these findings likely support the suspicions of many FL instructors, their relevance to FL education contexts is limited since the subjects were translators in training, rather than typical FL students.

Kumar (2012) attempted to study the use of MT systems including GT among students of business and IT. The purpose of the study was to examine the use and dependence on MT tools by Arab college students. The study used a survey approach through a questionnaire involving 60 students. The study result revealed that all students use MT systems and the application of GT was dominant. The results also revealed that over $75 \%$ of the students used GT mostly to understand the concepts taught in EFL classrooms. MT provides them with academic and scientific terms for writing assignments. Moreover, MT was very helpful for translation, reading comprehension and improvement in English. MT, however, could not provide a translation outcome at a linguistic accuracy level for academic assignments and reports. Therefore, students did not rely completely on its translation outcomes; however, they strongly agree that MT had assisted them in learning English.

In one survey, Korošec (2012) attempted to investigate the applicability and challenges of utilising MT in translator training. He focused on the modes as well as frequency of the application of internet, GT and GT tool kit among translation students at the undergraduate level. The study involved 33 students using a survey approach. The study found that freely accessible MT systems and platforms employed by students of translation offered a first draft and saved their time. He suggested that these MT systems need to be taken into consideration by teachers and provide learners with proper training and practice.

In a study assessing the quality of GT performance, Kadhim et al. (2013) selected 40 Arabic headlines from three online sources such as Aljazeera, Aawsat and Daralhayat whose English manually translated versions were accessible. The study distributed a questionnaire (Hutchins \& Somers, 1992) among 28 professional whose first language is Arabic. The study reported that both GT and Babylon had the clarity of $80 \%$, while GT scored higher in terms of accuracy $(77.5 \%$ ) where Babylon had an accuracy of 75\%; however, Babylon scored a higher value for style $(72.5 \%)$, whereas GT's score was $70 \%$.

Clifford et al. (2013) reported the first large-scale effort to collect data on FL learner and instructor use and perceptions of FOMT. In phase 1 of the study, researchers at Duke University asked 356 students enrolled in Spanish classes a few basic questions regarding frequency of MT use, reasons and purposes (assignment/task type) for using it, and beliefs about MT accuracy. Those inquiries were substantially expanded and refined in phase 2, which surveyed 905 students of Spanish and three other languages, as well as $43 \mathrm{FL}$ instructors. Both groups responded to items about MT tool use, including questions relating to academic dishonesty, output quality and implications for FL learning and teaching. Key findings included that students use MT on a regular basis for specific purposes, consider it to be helpful for their language learning and are generally aware that it produces errors. Instructor responses confirmed that 'faculty are skeptical of a positive impact on language learning' and that they see MT integration as being more useful in advanced courses (p. 116).

Sukkhwan and Sripetpun (2014) conducted a study to explore students use and attitudes 
towards using GT for aiding their English learning and problems in using GT, and explored the ways GT is employed by students to find solutions. They used a questionnaire, focusing on the purpose of students' GT use, attitudes, problems and solutions. One hundred twenty-five first year non-English major Thai students participated in the study. The results revealed that almost all students used GT but at a low level of frequency. Vocabulary learning, writing and reading were the three most frequent purposes for which students used GT, whereas translation was the least frequently used. Considering the learning purposes, the students most frequently used GT to get the meaning of unknown words, writing exercises or assignments, reading an English textbook and translating idioms and proverbs. The findings also showed that students viewed GT as more beneficial than disadvantageous. It is free and easily accessible. It provides a fast translation with better quality when compared with students' own translations.

Ganjalikhani (2014) examined the use of GT in translation of English sentences (simple, compound and complex) into Persian. The study used GT to translate different categories of sentences from English into Persian. The study has shown that GT is not capable of providing proper translation for English sentences and the system is yet to be developed and expanded.

In a study investigating the impact of GT on reading comprehension, Karnal and Pereira (2015) studied reading comprehension and the application of GT. The study analysed the strategies used by readers who use GT by using think aloud protocol. The study involved 10 intermediate students. It was reported that they used 26 strategies, and there was barely any difference among the strategies applied. The study indicated that the use of GT has encouraged learners to use more strategies and involved more cognitive demands and, accordingly, their comprehension was more effective.

Jolley and Maimone (2015) investigated Spanish students and instructors' perceptions of FOML. The survey dealt with the participants' use, attitudes and perceptions as well as beliefs about GT and similar MT systems. The study results showed that the students employed MT systems widely and the instructors also had positive views of using MT tools, especially GT. The study suggests that proper training needs to foster the effectiveness of the use of MT tools and GT.

\section{Methods}

\subsection{Subjects}

The participants in this study were 92 fourth-year English majors in the Department of English at Aljouf University in Saudi Arabia. They ranged in age from 22 to 26 with a mean of 23.7. Their native language is Arabic. They were selected randomly to participate in the study based on their willingness to participate.

\subsection{Instruments}

The research instrument used in this study was a questionnaire adapted from previous studies with some modifications. (Jolley \& Maimone, 2015; Korosec, 2012; Kumar, 2012; Sukkhwan 
\& Sripetpun, 2014; Jolley \& Maimone, 2015). Prior to the data collection, the validity and reliability of the questionnaire were determined. The study measured the reliability of the instrument through a pilot study using Cronbach's alpha (Creswell, 2013; Gass \& Mackey, 2007), and the results indicated that the instrument had a high level of internal consistency (.85). The data obtained from the questionnaire were analysed using descriptive statistics (mean and percentage).

\section{Results and Discussion}

Table 1. Frequency of Use of Google Translate

\begin{tabular}{|c|c|c|c|c|}
\hline \multicolumn{5}{|c|}{ Do you use Google translate? } \\
\hline \multicolumn{3}{|l|}{ Yes } & \multicolumn{2}{|l|}{ No } \\
\hline \multicolumn{3}{|l|}{$96.2 \%$} & \multicolumn{2}{|l|}{$3.8 \%$} \\
\hline \multicolumn{5}{|c|}{ How often do you use Google translate? } \\
\hline Never & Seldom & Sometimes & Often & Always \\
\hline $3.8 \%$ & $14.1 \%$ & $25.3 \%$ & $32 \%$ & $24.8 \%$ \\
\hline
\end{tabular}

The results in Table 1 show that almost all of the students $(96.2 \%)$ use Google translate while few of them (3.8\%) do not. The majority of the students selected 'often' and 'always' with the percentages of (32\%) and (24.8\%), respectively. The option selected the least is 'never' (3.8\%). The students selected the options 'sometimes' and 'seldom' with percentages of $(25.3 \%)$ and (14.1\%), respectively. An interesting point is that the options 'often' and 'always' were selected very closely. This means that half of the population use GT frequently, and a quarter of the participants sometimes make use of GT. This result concurs with previous studies found in the literature (Korosec, 2012; Clifford et al., 2013; Case, 2015), which found that the vast majority of the L2 learners use GT frequently. Kumar (2012) found in his study that the use of GT is dominant among Arab students. Sukkhwan and Sripetpun (2014) found that $93.6 \%$ of the Thai university non-English major students use GT. Moreover, they found that almost $42 \%$ of the students use GT frequently. Another study conducted by Clifford et al. (2013) on EFL students at Duke University found that $81 \%$ of the respondents reported using GT to support their language learning, which is significantly higher than that of any other tool.

In terms of frequency by purpose, the subjects reported using GT for vocabulary learning, writing, reading, translation and grammar structure, respectively. For vocabulary learning, students used GT most frequently to get the meaning of unknown words, followed by technical words. For writing, students reported using GT mostly to complete their English exercises and homework. They also claimed that they use GT in writing in order to choose words for online communication such as writing comments on Facebook and Twitter. For reading, the students used GT particularly to help them understand English sentences and texts in an English textbook, including those on websites. When it comes to translation, students reported that they use GT to translate idioms and proverbs. 
According to the results, students use GT mostly to learn vocabulary and also use it to facilitate their writing and reading. These findings are in line with Niño (2005) who found that his students used GT mostly for the purpose of writing and reading comprehension in foreign languages. Moreover, the findings agree with Kumar (2012) who found that Arab students used GT for the purpose of learning English. He found that they used GT mostly to understand concepts taught in their classrooms and used it most frequently when writing assignments, projects and reports.

\subsection{Students'Attitudes toward Using GT for English Learning Purposes}

Students reported that they use GT because it is free of charge, can be accessed easily and performs translation tasks quickly. Moreover, they mentioned that GT provides more advantages than disadvantages, and the quality of translated texts was better than their own translation. On the other hand, some students admitted that GT had some negative impacts on their learning habits. They rely heavily on GT, do not read the English text and cannot retrieve or guess the meaning of unknown words. Furthermore, they do not write English based on their own efforts and they rely on GT to help them. These findings showed that the students realise that GT has both benefits and drawbacks. They had positive attitudes toward GT as it is convenient to use and helpful for all the students to learn English and especially new words. The results agree with previous studies that found that learners' positive attitudes are encouraged when computers are used for language learning (Fujieda, 1999; Levine, Ferenz \& Reves, 2000). However, the subjects admitted that their attempts in reading and writing English were reduced, and they had problems with vocabulary retention when they used GT. These findings correspond to Kumar (2000) who found that Arab students viewed GT as helpful, but they could not learn English well because it affected their ability to think.

\subsection{Students' View on the Quality of GT Output and Ethics of Its Use}

With regard to students' view on the quality of GT output, the students judged the overall accuracy of GT to be higher (74\%) than its capacity to convey the content or message of a source text $(58.1 \%)$ or to handle grammatical structure $(21 \%)$. In terms of accuracy by genre or text type, $60.2 \%$ said that GT could be used to somewhat effectively $(46.22 \%)$ or effectively (13.98\%) translate informative technical texts. The percentages indicating the same degree of confidence were substantially lower for persuasive/advertising texts $(39.2 \%)$ and artistic/literary texts $(25.7 \%)$. These findings are similar to those of Jolley and Maimone's (2015) results about Spanish EFL students.

The length of the translation segment also affected students' judgment of GT accuracy. For example, a $74.91 \%$ majority of students indicated that GT can be used to somewhat effectively (50.91\%) or effectively (24\%) render individual words, while similar majorities of $64.75 \%$ and $75.45 \%$ indicated that they are very ineffective or ineffective at rendering paragraphs or entire texts, respectively. In addition to perceptions of accuracy, we asked students to assess the overall reliability of translations generated by Google Translate. A majority of students $(63.52 \%)$ characterised them as somewhat reliable $(55.81 \%)$ or reliable $(7.71 \%)$, with a $34.48 \%$ minority judging them to be somewhat unreliable $(28.13 \%)$ or very unreliable $(6.35 \%)$. They rated the overall reliability of Google Translate-produced 
translations 3.60 on $0-5$ point scale.

With regard to the ethicality or appropriateness of using GT tools to complete English assignments, most students $(86.72 \%)$ indicated that whether their use of GT constitutes cheating depends on how it is used. Just $12.50 \%$ of students reported seeing nothing wrong with using GT regardless of use. Students' ethicality judgment varied by assignment type. For example, a combined $74.80 \%$ judged GT use on writing assignments to be somewhat ethical $(44.09 \%)$ or completely ethical $(30.71 \%)$, with presentations and workbook/lab assignments trailing at $68.51 \%$ and $65.63 \%$, respectively. Just $38.28 \%$ judged GT tool use on translation assignments to be somewhat or completely ethical.

The purpose and length of the translation segment also affected students' judgment of GT ethicality. High percentages of students reported that using GT tools to verify their own hunches $(85.04 \%)$ or for help with vocabulary $(78.91 \%)$ is completely ethical. Whereas $77.34 \%$ judged using GT to translate individual words as completely ethical; $32.03 \%$ and $51.56 \%$ indicated that using GT to translate paragraphs or entire texts is completely unethical. In terms of the relationship between frequency of use and academic dishonesty, students associated cheating with more frequent usage rates.

\section{Conclusion}

This study aims to investigate Saudi EFL students' attitudes toward GT and the purpose behind using it. The results revealed that the vast majority of the subjects reported using GT. More than half of the participants mentioned that they use it often and always. Moreover, the findings showed that the students use GT frequently for learning vocabulary, writing, reading and translation, respectively. It is somewhat surprising that students report using GT tools more frequently on writing assignments than on translation assignments - a purpose they are arguably better suited for. This may relate to students' lack of training in translation in general and with respect to GT use in particular. It is also important to underscore that most students see GT as having a positive impact on their language learning and want instructors to cover strategies for effective use. The students had very positive attitudes toward GT as it is free and easy to use and translates text quickly; its translation is better than their own, and it is helpful for learning vocabulary. On the other hand, some disadvantages were reported by the subjects. They pointed out that GT cannot translate all words correctly and sometimes gives inappropriate word meanings, so they check the meaning in the dictionary to confirm it or seek help from their teachers or peers.

The results of the current study propose that recommendations for successful pedagogical responses to the reality of GT use by students should take into consideration the fact that students lack training in the use of these tools, that they nevertheless use them quite frequently, that they are confident - perhaps overly so - in their accuracy and reliability, that they do, in fact, associate certain types of uses with academic dishonesty, and that they are willing to look to their instructors for direction.

The results of the study showed that there is a need for a framework that addresses the 
pedagogical implications of GT use. Only very low percentages of the students reported having received any training on the use of GT. This kind of training is not incorporated into FL teaching methods courses, which is a serious oversight given the frequency with which students use GT to support their language learning. Instructors should familiarise themselves with the intended purposes, features, strengths and weaknesses of GT so that they are better equipped to it.

Taking into consideration student behaviours and views, such as those presented in this study, instructors should determine the kinds of GT use they will prohibit or allow in a given class, or even for certain types of assignments. They should clearly articulate rules and consequences to their students, both in course syllabi and during in-class discussions.

\section{References}

Abuelyaman, E., Rahmatallah, L., Mukhtar, W., \& Elagabani, M. (2014). Machine translation Arabic language: Challenges and keys. In Intelligent Systems, Modeling and Simulation (ISMS) 2014 5TH International Conference on (pp. 111-116). IEEE.

Calefato, F., Lanubile, F., \& Minervini, P. (2010). Can real-time machine translation overcome language barriers in distributed requirements engineering?. In Global Case, M. (2015). Machine translation and the disruption of foreign language learning activities. Elearning Papers, (45), 4-16.

Clifford, R., Granoien, N., Jones, D., Shen, W., \& Weinstein, C. (2004). The effect of text difficulty on machine translation performance--a pilot study with ILR-rated texts in Spanish, Farsi, Arabic, Russian and Korean. Defense Language Inst Monterey CA.

Creswell, J. W. (2013). Research design: Qualitative, quantitative, and mixed methods approaches. Sage publications.

Ganjalikhani, M. K. (2014). An investigation of Google translate machine in rendering English sentence structures into Persian. Proceeding of the Global Conference On Language Practice \& Information Technology (GLIT 2014) 9-10 June 2014 Kota Kinabalu, Sabah, Malaysia.

Gass, S. M., \& Mackey, A. (2007). Data elicitation for second and foreign language research. Psychology Press.

García, I. (2010). Can Machine Translation Help the Language Learner? ICT for Language Learning Proceedings 2010. Retrieved 14/9/2016 from http://conference.pixel-online.net/ ICT4LL2010/common/download/Proceedings_pdf/TRAD02-Garcia.pdf

Hampshire, S., \& Salvia, C. P. (2010). Translation and the internet: Evaluating the quality of free online machine translators. Quaderns. Rev. trad. 17, 197-209.

Jolley, J. R., \& Maimone, L. (2015). Free online machine translation: use and perceptions by Spanish students and instructors. Learn Language, Explore Cultures, TransformLives. pp. 
181-200.

Kadhim, K. A., Habeeb, L. S., Sapar, A. A., Hussin, Z., \& Lim Abdullah, M. M. R. T. (2013). TOJET: The Turkish Online Journal of Educational Technology, 12(2), 39-50.

Kalaja, P., \& Barcelos, A. (Eds.). (2003). Beliefs about SLA: New research approaches. Amsterdam: Kluwer Academic.

Karnal, A. R., \& Vera, P. W. (2015). Reading comprehension and the use of Google translator. International Journal of English Linguistics, 3(6), 133-118.

Károly, A. (2014). Translation in foreign language teaching: A case study from a functional perspective. Linguistics and Education, 25, 90-107.

Kirchhoff, K., Turner, A. M., Axelrod, A., \& Saavedra, F. (2011). Application of statistical machine translation to public health information: a feasibility study. Journal of the American Medical Informatics Association, 18(4), 473-478.

Kliffer, M. (2005). An experiment in MT post-editing by a class of intermediate/advanced French majors. In Proceedings EAMT 10th Annual Conference, Budapest, 160-165.

Korošec, M. K. (2012). Applicability and challenges of using machine translation in translator training. Elope Language, 7-18.

Kumar A. (2012). Machine translation in Arabic-speaking ELT classrooms: Applications and implications. International Journal of Social Science and Humanity, 2(6), 442-445.

McCarthy, B. (2004). Does online machine translation spell the end of take-home translation assignments? CALL-EJ Online, 6(1). Retrieved from http://callej.org/journal/6-1/mccarthy.html

Niño, A. (2008). Evaluating the use of machine translation post-editing in the foreign language class. Computer Assisted Language Learning, 21(1), 29-49.

Niño, A. (2009). Machine translation in foreign language learning: language learners' and tutors' perceptions of its advantages and disadvantages. ReCALL, 21(2), 241-258.

Savoy, J., \& Dolamic, L. (2010). How effective is Google's translation service in search? Communications of the ACM, 52(10), 139-143.

Sukkhwan, A., \& Sripetpun, W. (2014). Use of Google translate: A survey of Songkhla Rajabhat University students. International Proceedings of L-SA Workshop and Colloquium: "Speaking”for ASEAN, Thailand: Prince of Songkla University, 88-104.

Xiao, T., Li, Q., Lu, Q., Zhang, H., Ding, H., Yao, S., \& Wang, H. (2011). The NiuTrans Machine Translation System for NTCIR-9 PatentMT. In NTCIR. 


\section{Copyright Disclaimer}

Copyright for this article is retained by the author(s), with first publication rights granted to the journal.

This is an open-access article distributed under the terms and conditions of the Creative Commons Attribution license (http://creativecommons.org/licenses/by/3.0/). 